\title{
Pengujian Viskositas Minyak Limbah Biji Jambu Mente Hasil Pirolisis
}

\author{
Inong Oskar ${ }^{a}$ *, Andi Erwin Eka Putra ${ }^{\text {b }}$ \\ aJurusan Teknik Mesin, Fakultas Teknik, Universitas Atma Jaya Makassar \\ Jl.Tanjung Alang no 23, Kota Makassar \\ ${ }^{\mathrm{b}}$ Departemen Teknik Mesin, Fakultas Teknik, Universitas Hasanuddin \\ Jl. Malino, Borongloe, Bontomarannu, Kabupaten Gowa. \\ *E-mail: inongoskar18@gmail.com
}

\begin{abstract}
Renewable energy resources in Indonesia are very potential, where one of them is biomass potential. Based on the 2017 Indonesian Energy BPPT-Outlook data, the biomass energy resource potential is 32,654 Mwe. On the other hand, Indonesia is very rich in natural resources, one of which is cashew (Anacardium Occidentale), which cashew nut shells produce waste and have not been utilized optimally as a product that has economic value. Pyrolysis is a thermochemical decomposition of organic matter through a process of heating without or little oxygen or other chemical reagents, while viscosity is a measure to express the thickness of a solution or fluid. The purpose of this study was to determine the temperature and amount of production of oil, tar and viscosity values (from oil and tar) found in cashew nut shell waste using pyrolysis technology, the increase in temperature was measured by thermocouples, and the number of products produced was measured by scales digital while the value of the viscosity is measured by an Otswald viscometer. The method used is the experimental method. Cashew nut shell waste is heated to a temperature where oil and tar begin to come out or produce. The results showed that the oil production temperature from cashew nut shell waste starts from 218-245.5 oC while the level starts from $245.5-347^{\circ} \mathrm{C}$, with $85 \%$ oil production and $15 \%$ tar, the viscosity value for oil is $0.9528 \mathrm{cP}$ while the tar viscosity value is not detected because the sample was sticky on the viscometer wall.
\end{abstract}

Keywords: Waste; cashew; pyrolysis; viscosity

\section{Abstrak}

Sumber daya energi terbarukan di Indonesia sangat berpotensi, dimana salah satunya adalah potensi biomassa. Berdasarkan data BPPT-Outlook Energi Indonesia tahun 2017, potensi sumber daya energi biomassa sebesar 32.654 Mwe. Di sisi lain, Negara Indonesia sangat kaya sumber daya alam, salah satunya adalah jambu mete (Anacardium Occidentale), yang kulit biji (cangkang) jambu mente ini menghasilkan limbah dan belum dimanfaatkan secara maksima sebagai produk yang mempunyai nilai ekonomis. Pirolisis merupakan dekomposisi termokimia bahan organic melalui proses pemanasan tanpa atau sedikit oksigen atau pereaksi kimia lainnya, sedangkan viskositas merupakan ukuran untuk menyatakan kekentalan suatu larutan atau fluida. Tujuan penelitian ini adalah untuk mengetahui temperatur dan jumlah produksi dari minyak, tar dan nilai viskositas (dari minyak dan tar) yang terdapat pada limbah kulit biji jambu mente dengan menggunakan teknologi pirolisis, kenaikan temperature diukur dengan termokopel, dan jumlah produk yang dihasilkan diukur dengan timbangan digital sedangkan nilai viskositasnya diukur dengan viskometer Otswald. Metode yang digunakan adalah metode eksperimen. Limbah kulit biji jambu mente dipanaskan sampai pada temperatur dimana minyak dan tar mulai keluar atau berproduksi. Hasil penelitian diperoleh bahwa temperatur produksi minyak dari limbah kulit biji jambu mente mulai dari $218-245.5^{0} \mathrm{C}$ sedangkan tarnya mulai dari 245.5 $347^{\circ} \mathrm{C}$, dengan jumlah produksi minyak $85 \%$ dan tar $15 \%$, nilai viskositas untuk minyak $0.9528 \mathrm{cP}$ sedangkan nilai viskositas tar tidak terdeteksi karena sampel melengket di dinding viscometer.

Kata kunci: Limbah; jambu mente; pirolisis; viskositas

\section{Pendahuluan}

Sumber daya energi terbarukan di Indonesia sangat berpotensi, dimana salah satunya adalah potensi biomassa. Berdasarkan data BPPT-Outlook Energi Indonesia tahun 2017 [1], potensi sumber daya energi biomassa sebesar 32.654 Mwe. Biomassa adalah salah satu sumber energi terbarukan yang potensial dan konversi bahan tanaman menjadi bentuk energi yang cocok, biasanya listrik atau sebagai bahan bakar untuk mesin pembakaran dalam [2]. Di sisi lain, Negara Indonesia sangat kaya sumber daya alam, salah satunya adalah jambu mente (Anacardium 
Occidentale). Dikenal juga dengan berbagai nama seperti jambu mèdè (Sunda); jambu mété atau jambu ménté (Jawa) atau jambu monyet. Kulit mete mengandung minyak laka atau Cashew Nut Shell Liquid (CNSL), yang tidak dapat digunakan sebagai bahan pangan tetapi digunakan untuk berbagai macam keperluan industri [3]. Ekstraksi CNSL dari kulit biji jambu mete dilakukan dengan beberapa metode yakni : penyangraian, penggorengan, pengempaan dan ekstraksi dengan pelarut kimia [4]. Beberapa daerah di Indonesia masyarakatnya menggunakan arang kulit biji jambu mete untuk memanaskan kacang mete pada saat pengupasan kulit ari. Pemanfaatan limbah kulit biji mete sebagai energi alternatif belum maksimal. Produksi mete gelondongan dalam skala nasional berada di kisaran 156.000 ton per tahun, jumlah ini tidak mengalami peningkatan berarti selama 10 tahun terakhir. Penghasil mete utama adalah Sulawesi Tenggara (24,85 \% produksi nasional), Sulawesi Selatan, Sulawesi Tengah (17,89 \%), NTT, NTB, Bali (37,95 \%) serta Jawa- Madura (23,80 \%). Biji kacang mete umumnya memiliki berat rata-rata 5-6 gr, panjang 2,5-3,5 cm, lebar $2 \mathrm{~cm}$, dan tebal 1,0-1,5 cm. Berat kulit biji jambu mete rata-rata 70\% dan isi dagingnya (kernel) sebesar $30 \%$ [5] . Karena biji jambu mete terdiri atas kulit biji jambu mete $70 \%$ dari berat total biji jambu mete dan kernel $30 \%$ dari berat total biji jambu mete, kulit biji mete mengandung $32 \%$ - $37 \%$ cashew nut shell liquid (CNSL) atau minyak laka, maka dari produksi biji jambu mete ini diperoleh limbah kulit biji jambu mete sekitar 109.000 ton per tahun sehingga potensi ini cukup besar untuk dijadikan bahan bakar biomassa sebagai bahan bakar alternatif. Penelitian sebelumnya menunjukkan bahwa nilai viskositas limbah kulit biji jambu mente sebesar $543.33 \mathrm{cP}$ [6]. Adapun manfaat minyak laka (CNSL) di bidang industri antara lain sebagai bahan baku oli rem mobil dan pesawat terbang, Perekat kayu pada industri kayu lapis nasional. Pemanfaatan minyak kulit mete atau CNSL sebagai perekat kayu lebih memberikan jaminan keamanan karena tidak menimbulkan penyakit kulit dan infeksi saluran nafas sebagaimana dampak negatif yang bisa ditimbulkan oleh fenol formaldehide, bahan pestisida nabati [3].

Cashew Nut Shell Liquid (CNSL), yang sangat penting bagi industri diperoleh dari biji pericarp (cangkang) [7]. Kulit dari pengolahan kacang mete mengandung energi yang tinggi dan berpotensi menggantikan kayu bakar untuk aplikasi termal di pabrik. Namun, pembakaran langsung cangkang kacang mete itu merepotkan karena efisiensi rendah dan emisi asap yang tinggi [8]. Sehingga untuk mendapatkan produk baru misalnya gas, minyak, tar ataupun arang dari limbah kulit biji jambu mente ini memerlukan teknologi gasifikasi atau pirolisis [9]. Beberapa keunggulan dari teknologi gasifikasi yaitu: Mampu menghasilkan produk gas yang konsisten yang dapat digunakan sebagai pembangkit listrik; mampu memproses beragam input bahan bakar termasuk batu bara, minyak mentah berat (heavy crude oil), biomassa, berbagai macam sampah kota (municipal waste), dan lain sebagainya; mampu mengubah sampah yang bernilai rendah menjadi produk yang bernilai lebih tinggi; mampu mengurangi jumlah sampah padat dan; gas yang dihasilkan tidak mengandung furan dan dioksin yang berbahaya. Sampai saat ini di Indonesia kulit biji jambu mete belum dimanfaatkan secara maksimal, sebagian besar masih merupakan limbah, sehingga produksi CNSL di Indonesia masih sangat rendah. Padahal potensi produksi CNSL di Indonesia sebenarnya cukup besar, oleh karena itu mengingat berbagai manfaat CNSL dan turunannya pada berbagai industri, serta keunggulannya dalam susunan struktur molekul maupun keunggulan sebagai bahan terbarukan yang ramah lingkungan, maka sudah saatnya potensi CNSL yang terkandung dalam kulit biji jambu mete tersebut di daya gunakan dan dikembangkan dengan baik [4]. Meskipun produksi gas sintetik pada awalnya memanfaatkan teknologi pirolisis [10], tapi saat ini pirolisis lebih banyak diaplikasikan untuk memproduksi bio-oil dari bahan baku biomassa. Metode yang dipakai adalah flash pyrolisis, dimana biomassa dipanaskan secara cepat tanpa oksigen pada temperatur tinggi antara $450^{\circ} \mathrm{C}-600^{\circ} \mathrm{C}$, dengan waktu tinggal gas (residence time) yang pendek yaitu kurang dari 1 detik. Pirolisis [11] merupakan dekomposisi termokimia bahan organik melalui proses pemanasan tanpa atau sedikit oksigen atau pereaksi kimia lainnya, Pirolisis biasanya merupakan reaksi kimia pertama yang terjadi dalam terbakarnya banyak bahan bakar organik padat, seperti kayu, kain, dan kertas, dan juga beberapa jenis plastik. Dalam api pembakaran kayu, api terlihat bukan karena pembakaran kayu itu sendiri, melainkan dari gas yang dilepaskan dari proses pirolisis tersebut.

Viskositas merupakan ukuran untuk menyatakan kekentalan suatu larutan atau fluida. Viskositas juga dapat diartikan sebagai ketahanan aliran fluida yang disebabkan adanya gaya gesek antara molekul-molekul cairan satu sama lain. Viskositas dapat diukur dengan cara mengukur laju aliran suatu fluida yang melewati tabung berbentuk silinder. Alat untuk mengukur viskositas adalah viskometer. Ada beberapa macam viskometer, antara lain viskometer Ostwald, viskometer Hoppler viskometer Cup and Bob, dan viskometer Cone and Plate. Pada percobaan ini untuk mengukur waktu alir larutan digunakan viskometer Ostwald yang dilakukan dengan mengukur lamanya laju aliran minyak/tar dari limbah kulit biji jambu mente hasil pirolisis.

Berdasarkan uraian di atas maka tujuan penelitian ini adalah untuk mengetahui besarnya temperatur dan jumlah produksi dari minyak, tar dan nilai viskositas (dari minyak dan tar) yang terdapat pada limbah kulit biji jambu mente. Teknologi yang digunakan adalah teknologi pirolisis dan nilai viskositasnya diukur dengan viscometer Otswald.

\section{Material dan Metode Penelitian}

Material (sampel) yang digunakan dalam penelitian ini adalah limbah kulit biji (cangkang) jambu mente yang diambil dari desa Labasa Kabupaten Muna Sulawesi Tenggara. Adapun metode yang digunakan dalam penelitian ini adalah metode eksperimen. Proses pemanasan untuk menghasilkan produk minyak dan tar dilakukan di Laboratorium terpadu Universitas ATma Jaya Makassar, sedangkan proses pengujian produk minyak dan tar dilakukan di Laboratorium Kimia-Fisiska Universitas Hasanuddin. Peralatan yang digunakan antara lain: timbangan digital, reaktor 
pirolisis, termokopel, tungku pembakaran, pompa air aquarium, gelas ukur dan satu set viskometer Ostwald. Gambaran proses penelitian seperti pada diagram alir berikut ini:

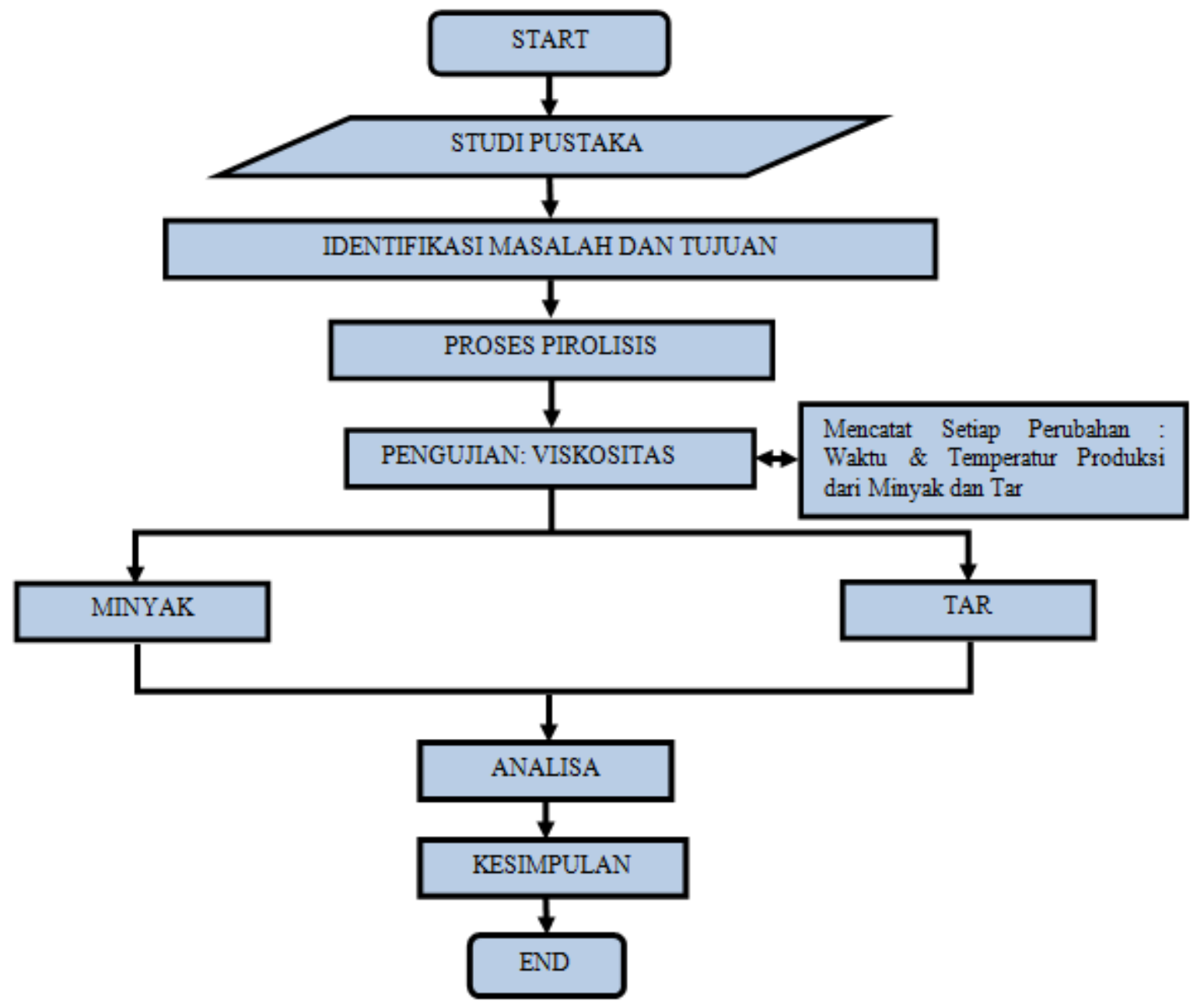

Gambar 1. Diagram alir penelitian.

\section{Hasil dan Pembahasan}

Pada proses pemanasan ini menghasilkan tiga produk utama yaitu arang, minyak/tar dan gas. Massa (weight) limbah kulit biji jambu mente gelondongan sebelum pemanasan sebesar $0.5 \mathrm{~kg}$.

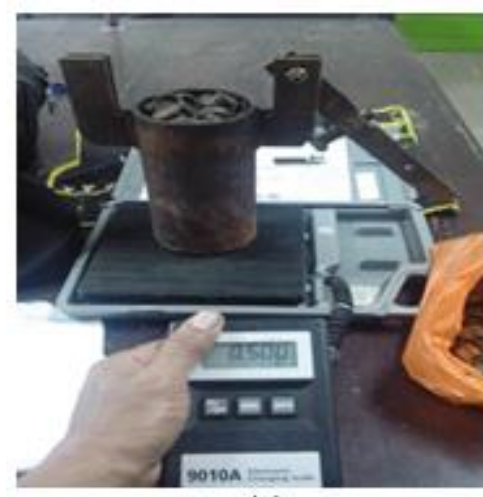

(a)

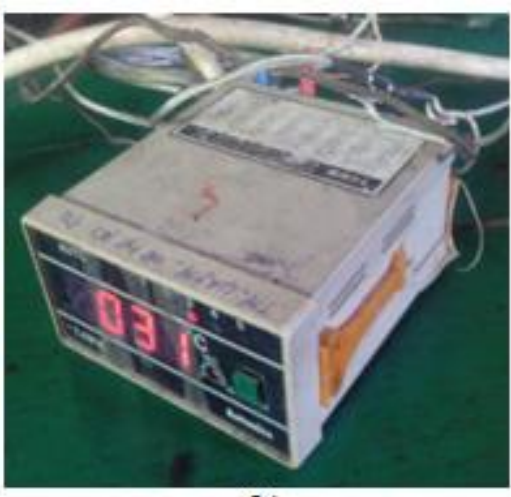

(b)

Gambar 2. (a) Gambar proses penimbangan limbah kulit biji jambu mente; (b) Thermokopel 
Massa (weight) produk minyak dan tar hasil pirolisis atau setelah pemanasa rata-rata, sebagai berikut:

a. Minyak adalah $0.2975 \mathrm{~kg}$ atau $59.5 \%$

b. Tar adalah $0.0525 \mathrm{~kg}$ tar atau $10.5 \%$. Sedangkan produk sampingan lain sebesar $30 \%$ berupa arang dan gas. Waktu terjadinya produksi minyak dan tar, kondisi temperatur dan tekanan saat terjadinya produksi minyak keluar dari reaktor pirolisis ditunjukkan pada tabel 1 berikut ini:

Tabel 1. Waktu, Kondisi temperature dan tekanan saat produksi minyak

\begin{tabular}{|c|c|c|c|c|c|c|}
\hline \multirow{2}{*}{ No. } & \multirow{2}{*}{$\begin{array}{l}\text { Waktu } \\
\text { (min) }\end{array}$} & \multicolumn{4}{|c|}{ Temperatur $\left({ }^{\circ} \mathrm{C}\right)$} & \multirow{2}{*}{$\begin{array}{c}\text { Temperatur } \\
\text { Produksi } \\
\text { Minyak } \\
\left({ }^{\circ} \mathrm{C}\right)\end{array}$} \\
\hline & & $T \infty$ & $T_{1}$ & $T_{2}$ & $T_{3}$ & \\
\hline 1 & 0 & 27 & 27 & 35 & 27 & \\
\hline 2 & 2 & 27 & 27 & 38 & 32 & \\
\hline 3 & 4 & 27 & 27 & 42 & 38 & \\
\hline 4 & 6 & 27 & 27 & 50 & 42 & \\
\hline 5 & 8 & 27 & 27 & 56 & 51 & \\
\hline 6 & 12 & 27 & 27 & 76 & 56 & \\
\hline 7 & 14 & 27 & 27 & 90 & 64 & \\
\hline 8 & 16 & 27 & 27 & 98 & 70 & \\
\hline 9 & 18 & 27 & 27 & 113 & 78 & \\
\hline 10 & 20 & 27 & 27 & 127 & 91 & \\
\hline 11 & 22 & 27 & 27 & 148 & 104 & \\
\hline 12 & 24 & 27 & 27 & 164 & 122 & \\
\hline 13 & 26 & 27 & 27 & 185 & 132 & \\
\hline 14 & 28 & 27 & 27 & 202 & 156 & \\
\hline 15 & 30 & 27 & 28 & 222 & 176 & \\
\hline 16 & 32 & 27 & 28 & 240 & 195 & \\
\hline 17 & 34 & 27 & 28 & 262 & 212 & \\
\hline 18 & 36 & 27 & 28 & 284 & 220 & 218 \\
\hline 19 & 38 & 27 & 28 & 306 & 238 & 216 \\
\hline 20 & 40 & 27 & 28 & 325 & 256 & 240 \\
\hline 21 & 42 & 27 & 28 & 349 & 280 & \\
\hline 22 & 44 & 27 & 28 & 368 & 304 & \\
\hline 23 & 46 & 27 & 28 & 388 & 326 & \\
\hline 24 & 48 & 27 & 28 & 407 & 348 & 348 \\
\hline 25 & 50 & 27 & 28 & 428 & 368 & \\
\hline 26 & 52 & 27 & 28 & 446 & 387 & \\
\hline
\end{tabular}

Ket. :

T $\infty=$ Temperatur udara sekeliling;

$\mathrm{T}_{1}=$ Temperatur pada pipa pendingin;

$\mathrm{T}_{2}=$ Temperatur pada dinding reaktor;

$\mathrm{T}_{3}=$ Temperatur dalam reaktor 
Tabel 2. Pemanasan limbah kulit biji jambu mente pada reaktor pirolisis (Percobaan II)

\begin{tabular}{|c|c|c|c|c|c|c|}
\hline \multirow{2}{*}{ No. } & \multirow{2}{*}{$\begin{array}{l}\text { Waktu } \\
\text { (min) }\end{array}$} & \multicolumn{4}{|c|}{ Temperatur $\left({ }^{\circ} \mathrm{C}\right)$} & \multirow{2}{*}{$\begin{array}{c}\text { Temperatur } \\
\text { Produksi } \\
\text { Minyak } \\
\left({ }^{\circ} \mathrm{C}\right)\end{array}$} \\
\hline & & $\mathbf{T} \infty$ & $\mathbf{T}_{1}$ & $\mathbf{T}_{2}$ & $\mathbf{T}_{3}$ & \\
\hline 1 & 0 & 27 & 27 & 35 & 27 & \\
\hline 2 & 2 & 27 & 27 & 40 & 33 & \\
\hline 3 & 4 & 27 & 27 & 46 & 38 & \\
\hline 4 & 6 & 27 & 27 & 51 & 44 & \\
\hline 5 & 8 & 27 & 27 & 57 & 51 & \\
\hline 6 & 12 & 27 & 27 & 76 & 58 & \\
\hline 7 & 14 & 27 & 27 & 91 & 65 & \\
\hline 8 & 16 & 27 & 27 & 98 & 71 & \\
\hline 9 & 18 & 27 & 27 & 114 & 80 & \\
\hline 10 & 20 & 27 & 27 & 128 & 93 & \\
\hline 11 & 22 & 27 & 27 & 148 & 107 & \\
\hline 12 & 24 & 27 & 27 & 164 & 123 & \\
\hline 13 & 26 & 27 & 27 & 185 & 134 & \\
\hline 14 & 28 & 27 & 27 & 203 & 157 & \\
\hline 15 & 30 & 27 & 28 & 223 & 177 & \\
\hline 16 & 32 & 27 & 28 & 242 & 197 & \\
\hline 17 & 34 & 27 & 28 & 264 & 213 & 218 \\
\hline 18 & 36 & 27 & 28 & 284 & 222 & 210 \\
\hline 19 & 38 & 27 & 28 & 307 & 240 & 215 \\
\hline 20 & 40 & 27 & 28 & 326 & 258 & $24 J$ \\
\hline 21 & 42 & 27 & 28 & 348 & 282 & \\
\hline 22 & 44 & 27 & 28 & 367 & 305 & \\
\hline 23 & 46 & 27 & 28 & 388 & 327 & 346 \\
\hline 24 & 48 & 27 & 28 & 408 & 348 & U \\
\hline 25 & 50 & 27 & 28 & 430 & 367 & \\
\hline 26 & 52 & 27 & 28 & 448 & 387 & \\
\hline
\end{tabular}

Pengujian viskositas minyak dan tar menggunakan sampel sesudah melalui proses pemanasan. Hasil Pengujian viskositas minyak dan tar pada kulit biji jambu mente diperoleh data yang ditunjukkan pada tabel 3 berikut ini:

Tabel 3. Hasil Pengujian Minyak dan Tar

\begin{tabular}{clll}
\hline No. & \multicolumn{1}{c}{ Jenis Sampel } & \multicolumn{1}{c}{$\begin{array}{c}\text { Berat Jenis } \\
\left(\mathrm{g} / \mathrm{cm}^{3}\right)\end{array}$} & \multicolumn{1}{c}{$\begin{array}{c}\text { Viscositas } \\
(\mathrm{cP})\end{array}$} \\
\hline 1. & $\begin{array}{l}\text { Minyak Kulit Biji Jambu } \\
\text { Mente }\end{array}$ & 1.0130 & 0.9528 \\
2. & Tar Kulit Biji Jambu Mente & 1.0074 & $\begin{array}{l}\text { Sampel lengket di } \\
\text { dinding viscometer }\end{array}$ \\
\hline
\end{tabular}




\section{Kesimpulan}

Produksi biji jambu mete dengan limbah kulit biji jambu mete sekitar 109.000 ton per tahun sangan berpotensi untuk menjadi bahan baku siap pakai seperti minyak dan tar dengan teknologi pirolisis. Hasil penelitian diperoleh bahwa temperatur produksi minyak dari limbah kulit biji jambu mente mulai dari $218-245.5^{\circ} \mathrm{C}$ sedangkan tarnya mulai dari $245.5-347{ }^{\circ} \mathrm{C}$, dengan jumlah produksi minyak $85 \%$ dan tar $15 \%$, nilai viskositas untuk minyak $0.9528 \mathrm{cP}$ sedangkan nilai viskositas tar tidak terdeteksi karena sampel melengket di dinding viscometer.

\section{Ucapan Terima Kasih}

Peneliti mengucapkan limpahan terima kasih kepada Kepala Laboratorium Terpadu Universitas Atma Jaya maupun Kepada Kepala Laboratorium Kimia-Fisika Universitas Hasanuddin yang telah memfasilitasi dan memberikan segala dukungan dalam proses pengambilan data.

\section{Daftar Pustaka}

[1] Energi O. BPPT- Outlook Energi Indonesia 2017. 2017. 93 p.

[2] McKendry P. Energy production from biomass (part 2): Conversion technologies. Bioresour Technol. 2002;83(1):47-54.

[3] Cahyaningrum A, Setyowati T, Nur A. Ekstraksi Cashew Nut Shell Liquid ( Cnsl ) Dari Kulit Biji Mete $\square$ S $\square$. 2006;5(1):40-5.

[4] Towaha J, Ahmadi NR. Pemanfaatan Cashew Nut Shell Liquid Sebagai Sumber Fenol Alami Pada Industri. 2011;2(2):187-98.

[5] Arif, Effendy. Oskar, Inong. P Y. Pengolahan Limbah Kulit Jambu Mente Sebagai Sumber Bahan Bakar Alternatif. 2008;(November):1-7.

[6] Budi Warsono, Lukas. Atmaka, Windi. Sigit Amanto B. Ekstraksi cashew nut shell liquid (cnsl) dari kulit biji mete dengan menggunakan metode pengepresan extraction cashew nut shell liquid (cnsl) from chasew nut shell using pressing method. Teknosains Pangan. 2013;2(2):84.

[7] A IP, I SM, A MM. Extraction and Characterization of Cashew Nut (Anacardium Occidentale) Oil and Cashew Shell Liquid Oil. Acad Res Int [Internet]. 2014;5(3):50-4. Available from: www.savap.org.pk\%5Cnwww.journals.savap.org.pk

[8] Tippayawong N, Chaichana C, Promwungkwa A, Rerkkriangkrai P. Application of Biomass Gasification System as a Sustainable Energy Technology to Improve Efficiency and Reduce Smoke Emission from Sterilization of Mushroom Growing Substrates. :5.

[9] Roddy DJ, Manson-Whitton C. Biomass gasification and pyrolysis. Vol. 5, Comprehensive Renewable Energy. 2012. 133-153 p.

[10] Zeolit A. Jurnal Kimia Sains dan Aplikasi Pirolisis Kulit Biji Jambu Mete ( Cashew Nut Shell ) dengan Katalis. 2012;15(3):100-4.

[11] Higman C, van der Burgt M. Gasification. El Sevier. 2003. 403 p. 